\title{
“Os Transparentes" de Ondjaki: Luanda como metáfora de Angola
}

\section{Ondjaki's "Transparent City": Luanda as a metaphor for Angola}

Isabel Ferin Cunha ${ }^{1}$

Resumo: Este artigo analisa a obra Os transparentes do escritor angolano Ondjaki, a partir dos conceitos de memória, nostalgia e ficção, no cenário da cidade de Luanda, entendida como metáfora de Angola. Recorrendo aos trabalhos de Baccega sobre Mayombe de Pepetela, inicia-se a exposição traçando o contexto em que se inscreve o romance de Ondjaki. Assinala-se, a partir de excertos da obra, como o autor ficciona personagens e interesses da cidade de Luanda, nomeadamente os de uma elite afeta ao ex-presidente, que governou o país por cerca de 40 anos. Em seguida, evocando mais uma vez Baccega, analisa-se como são construídas as personagens, numa dicotomia ganhadores/perdedores, e num cenário urbano progressivamente caótico e corrumpido, onde a memória e a nostalgia são âncora da resiliência dos despossuídos. Por fim, são mapeadas as referências e o papel das mídias, com principal relevância para o Jornalismo em Angola e a influência das telenovelas brasileiras.

Palavras-chave: Ondjaki; literatura angolana; ficção, mídias em Angola.

Abstract: This article analyzes the work Transparent City of the Angolan writer Ondjaki, based on the concepts of memory, nostalgia and fiction, in the scenario of Luanda city, understood as a metaphor for Angola. Using Baccega's works on Pepetela's Mayombe, we trace the context in which Ondjaki's novel is inscribed. It is pointed out, from work excerpts, how the author fictionalizes characters and interests of Luanda city, namely the elite that supports the ex-president who ruled the country for about forty years. Evoking Baccega once again,

1 Universidade Nova de Lisboa (ICNOVA). Lisboa, Portugal.

https://orcid.org/0000-0001-8701-527X. E-mail: barone.ferin@gmail.com. 
444 “OS TRANSPARENTES" DE ONDJAKI

we analyze how characters are constructed, in a dichotomy of winners/losers, and in a progressively chaotic and corrupt urban scenario, where memory and nostalgia are the anchor of dispossessed resilience. Finally, we map references and the role of the media, focusing the relevance of Journalism in Angola and the influence of Brazilian soap operas.

Keywords: Ondjaki; Angolan literature; fiction, media in Angola. 


\section{Introdução}

Este texto celebra a amizade e os sonhos libertários da amiga, colega e mestre Maria Aparecida Baccega. Na sua tese de doutoramento em Letras, defendida na Universidade de São Paulo, em 1986, intitulada Mayombe: ficção e história (uma literatura em movimento), debruçou-se sobre a literatura angolana, elegendo para análise a obra clássica Mayombe (1980), do escritor angolano Pepetela. O objetivo da autora foi discutir o papel da literatura em momentos de ruptura histórica, tal como aconteceu no fim do colonialismo em Angola, e a sua contribuição para a emergência de novas estruturas ideológicas, históricas e sociológicas. Neste sentido, a obra Os transparentes do angolano Ondjaki, que se pretende analisar, constitui um texto instigador - passados mais de 40 anos da escrita de Mayombe e da independência de Angola - ao denunciar, de forma desassombrada, as graves contradições da sociedade e a desesperança daqueles que combateram por uma sociedade mais digna e justa. Uma temática que assume relevância na conjuntura atual do Brasil e surge como um caminho a explorar, nesta fase da obra intelectual de Maria Aparecida Baccega.

Os transparentes (2012) é um romance ambientado em Luanda, na segunda década do século XXI, que conta a história de Odonato, um antigo funcionário público, e de um vasto grupo de personagens, as quais representam não só a sociedade luandense, mas também Angola. O enredo é construído em torno da crescente transparência, em sentido literal, do protagonista, que deixou de comer para alimentar os filhos, após não conseguir um emprego, porque em "Luanda, quem não tem jeito para esquemas...” (ONDJAKI, 2012, p. 282). Mas, na fala do protagonista, aquela característica, que se acentua, progressivamente, ao longo do romance, deve-se a uma outra realidade, “...nós somos transparentes porque somos pobres” (ONDJAKI, 2012, p. 203).

Na obra surgem, ficcionadas, as especificidades do regime angolano, dos esquemas e negócios de sobrevivência e corrupção - nomeadamente em torno da exploração de petróleo - que perpassam, transversalmente, toda a sociedade e deixam gradualmente "invisíveis", e despossuídos, 
os cidadãos comuns. Uma trama, onde o autor recorre a diversos registros literários, incluindo o humorístico, utilizando nuances da língua portuguesa, para descrever os constrangimentos e desafios da sociedade angolana, como, por exemplo, o anúncio do falecimento oficial da "senhora Ideologia", em uma enorme manchete do Jornal de Angola (ONDJAKI, 2012, p. 331).

A análise da obra fundamenta-se, em termos metodológicos, numa perspectiva interpretativista que privilegia a construção da ciência, a partir de uma abordagem subjetiva. Este pressuposto determina empreender um percurso de descoberta fundado na declaração de princípios e na enunciação de conceitos, com a finalidade de explorar e compreender o significado que indivíduos ou grupos atribuem a um problema social ou humano (CRESWELL, 2009, p. 4). Com esta orientação, esboça-se o contexto histórico e social que envolve o romance Os transparentes e convocam-se elementos da história e da sociologia de Luanda. Recorre-se, também, a princípios da Sociologia Literária (GOLDMANN, 1974; BACCEGA, 1990), nomeadamente aos estudos sobre a construção de personagens (CÂNDIDO, 2007; REIS; LOPES, 2002), bem como aos conceitos de memória (POLLACK, 1992; BARONE, 2005) e nostalgia (PICKERING; KELGHTLEY, 2006).

\section{Mayombe e Os transparentes: as obras e o seu tempo histórico}

Em um artigo, inspirado na tese de doutoramento, publicado na Revista do Centro de Estudos Africanos da USP, com o título "O movimento entre a ficção e a história. O caso Mayombe" (BACCEGA, 1990), a autora afirma que aquele romance "trata do cotidiano de uma Base de Guerrilheiros, durante as lutas de libertação de Angola” onde "cada membro da Base tem origem étnica diferente e mantém sua individualidade", mas, apesar das diversas origens, "o que conta, porém, é o projeto comum de vencer o colonialismo" (BACCEGA, 1990, p. 143-145). Esta enunciação tem grande atualidade, em função da polarização política, 
racial e social em que as sociedades, nomeadamente o Brasil, se movem. Os "objetivos comuns", o "bem comum" são mais importantes que as "diferenças particulares". Ensinamentos que não podem, contudo, fazer esquecer, segundo a autora, que "a manifestação do harmonioso das raças" é "uma das ficções do nosso país” (BACCEGA, 1990, p. 145). Embora, como afirma Celso Frederico (2020), o facto dessa harmonia ser "um mito" apontar para "um relato, um sonho, que revela profundas aspirações sociais e valores latentes..." que "projeta um futuro de reconciliação...uma democracia a-racial em que a cor da pele dos indivíduos será finalmente uma característica insignificante".

Baccega (1986; 1990) descreve e analisa a sociedade e a história de Angola, em Mayombe, de Pepetela, a partir de uma visão libertadora do MPLA (Movimento para a Libertação de Angola), onde estão "presentes como motivos ficcionais as grandes questões que caracterizam aquele momento do processo histórico, como o tribalismo, a identidade nacional, a cultura, a educação e escolarização, o partido, a relação teoria-prática, o papel do intelectual, a questão da violência" (BACCEGA, 1990, p. 147).

Recorda-se que o pensamento inspirador de Baccega, presente nos textos sobre Angola, foi materializado em cursos que promoveu sobre a África - em que tive o privilégio de participar - no final da década de 1980, na Escola de Comunicações e Artes da USP. Esses seminários, com títulos sugestivos, como "Para entender melhor a África" (19871988), envolveram professores e especialistas que abordaram de forma inovadora questões como sociedades tradicionais, demografia, religião, política e representações simbólicas. Nesses cursos, organizados pela Professora Baccega, participaram professores como Dilma de Melo, Fernando Mourão, Maria Aparecida Santilli, Kabengele Munanga e outros.

O presente trabalho procura, deste modo, homenagear o pioneirismo da Professora Baccega nos estudos sobre Angola e África. A obra Os transparentes (2012), do escritor angolano Ondjaki, Ndalu de Almeida, nascido em 1977, integra uma vasta obra literária, situada em Luanda, que perpassa o período que vai da declaração de independência (1l de 
novembro de 1975) à atualidade. Os transparentes refere-se aos anos finais do governo do Presidente José Eduardo dos Santos, que governou Angola por 38 anos (1979-2017) e conduziu o Movimento Popular para a Libertação de Angola (MPLA) durante igual período. Com a saída de José Eduardo dos Santos, assiste-se a uma reorganização do regime, onde a "luta contra a corrupção" entra no discurso quotidiano do novo presidente João Lourenço. ${ }^{2}$ Os negócios da família do ex-presidente, e da elite que a rodeou, foram expostos nacional e internacionalmente, sendo o designado escândalo de Luanda Leaks o grande promotor dessas investigações criminais (International Consortium of Investigative Journalists, 2020). ${ }^{3}$

Em Os transparentes é ficcionada a incúria e a ganância de uma elite política associada ao MPLA, capaz de destruir, a seu proveito, a sociedade angolana. A extração de petróleo em Luanda e os interesses que se articulam em torno dessa "prospecção" constituem a metáfora daquela realidade, iluminadas no romance, a partir da conversa entre um empresário, DomCristalino, e um Ministro, SantosPrancha: ${ }^{4}$

[...] (Ministro) a extração de petróleo vai avançar, disso já ninguém duvida. mas o Chefe está muito preocupado...as bocas da oposição, e as próprias preocupações do Presidente ...; (Cristalino) a cidade capital é de todos nós...e vamos avançar...depois das escavaçõe, vocês orientam-se com o petróleo. eu quero é a água...[...] (ONDJAKI, 2012, p. 191-192).

Com este texto, pretende-se prosseguir na mesma trilha de Baccega e analisar como, cerca de 40 anos depois, Ondjaki, um jovem escritor, interlaça literatura, ficção e história, no sentido de construir um grande

2 Cfr.: João Lourenço diz que luta contra corrupção vai continuar apesar da "resistência organizada”. Público, 13/03/2020. Disponível em: https://www.publico.pt/2020/03/13/mundo/ noticia/joao-lourenco-luta-corrupcao-vai-continuar-apesar-resistencia-organizada-1907589.

3 Cfr.: International Consortium of Investigative Journalists, O Império de Isabel: como a filha do ex-presidente de Angola aproveitou o poder político do pai para, com empresas de fachada e informações privilegiadas, se tornar a mulher mais rica de África. 19/01/2020. Disponível em: https://apublica.org/2020/01/o-imperio-de-isabel/.

4 Segue-se a ortografia utilizada por Ondjaki, nos nomes, nas citações e excertos da obra Os transparentes. 
quadro da sociedade angolana, tendo como cenário Luanda, na primeira década do século XXI.

Em Angola a independência foi declarada após 14 anos de luta contra a presença portuguesa, que colonizou durante 500 anos o território. Num contexto de guerra fria mundial e de uma nova partilha da África, seguiram-se mais de 20 anos de guerra civil entre os três principais movimentos de libertação - o MPLA, a UNITA e a FNLA - apoiados por potências estrangeiras. Especificando, o MPLA, o partido com maior número de quadros e apoiantes, foi liderado por Agostinho Neto e instalou-se em Luanda, tendo sido socorrido por cubanos e russos; a UNITA (União Nacional para a Independência Total de Angola), sediada na região centro de Angola, de etnia ovimbundo, foi liderada por Jonas Savimbi e apoiada pela África do Sul; a FNLA (Frente Nacional de Libertação de Angola), de maioria bacongo, implantada no Norte de Angola, foi financiada pelos Estados Unidos e liderada por Holden Roberto. O conflito durou 27 anos, de 1975 a 2002, e terminou com a morte do líder da UNITA e a transformação deste movimento em partido político.

A guerra, e a vitória do MPLA, fez com que se instalasse em Angola, sobretudo em Luanda, uma nomenclatura constituída por membros poderosos daquele partido político e dos generais que ganharam a guerra (OLIVEIRA, 2015). Os negócios, associados ao petróleo e aos diamantes, foram distribuídos pelos familiares e fiéis do Presidente Eduardo dos Santos, situação que parece estar a ser revertida pelo atual presidente João Lourenço, ${ }^{5}$ eleito em agosto de 2017 (CUNHA, 2020, p. 28-39). Os transparentes aborda o período "áureo" do governo de José Eduardo dos Santos, do preço do petróleoalto, que promoveu a "distribuição" de benesses e a consolidação de "esquemas" de corrupção, onde foi envolvido todo o aparelho do Estado, desde ministros a funcionários menores. A obra ilustra, igualmente, as consequências dessa "patologia" social, mostrando os efeitos perversos e a degradação do tecido social, político

5 Cfr.: Peres, Cristina. Angola está mesmo a mudar? Expresso Sociedade, 08/02/2020. Disponível em: https://expresso.pt/sociedade/2020-02-08-Angola-esta-mesmo-a-mudar-. 
e econômico. Recorde-se que, na sua acepção mais abrangente, corrupção diz respeito à apropriação indevida de bens ou ganhos e envolve três grandes cenários: i) a degradação do sentido ético dos agentes envolvidos; ii) um conjunto de práticas sociais predatórias no interior de determinadas instituições; iii) a apropriação indevida de benefícios, por agentes que se colocam em mútuo acordo (GAMBETTA, 2002).

\section{Luanda: da história colonial à metáfora da nação angolana}

$\mathrm{Na}$ época colonial, Luanda nasceu como entreposto comercial de escravos direcionado ao Atlântico (GONÇALVES, 2010), preferencialmente para o Brasil, e expandiu-se à medida que se estabeleceram relações com as "aristocracias pré-coloniais, com relevo para o Kongo, Matamba, Ndongo e Lunda” (GONÇALVES, 2010:4, citando TIDIANE DIAKITÉ, 2009). As trocas comerciais fixaram uma burguesia mestiça local, no século XIX (MOURÃO, 1996; BITTENCOURT, 2000; NASCIMENTO, 2013), constituída por comerciantes residentes e por aqueles que faziam incursões comerciais no mato, homens designados por pombeiros. Estes últimos mantinham as ligações entre as regiões do interior, sob jurisdição dos reinos nativos, e a costa, promovendo o tráfico de escravos e a venda de manufaturas europeias e portuguesas, bem como do vinho. O abandono de Luanda pelos poderes públicos portugueses, ao longo do período colonial, promoveu o aumento e a autonomia da cidade e a hegemonia de uma população mestiça, que se afirmou frequentemente diante da metrópole (MOURÃO, 1996, p. 58-60). Esta situação só se alterou após o "Ultimato Inglês" (1890)6 (ALEXANDRE, 2002), mas, principalmente, a partir da reorganização da política ultramarina do Estado Novo português (ALEXANDRE, 1993), efetivada nos anos 1950 do século XX.

6 Ultimato Inglês (1890) - memorando do governo inglês chefiado por Lord Salisbury exigindo que Portugal cumprisse o acordo sobre África, assinado na Conferência de Berlim, e se retirasse dos territórios entre Angola e Moçambique. 
A urbanização de Luanda iniciou-se no final do século XVIII, início do século XIX. Foram construídos arruamentos e a ligação entre os edifícios públicos, bairros e casas de alvenaria, originando a distinção entre a cidade baixa e a cidade alta. Em ambos os espaços prevaleceu uma toponímia Kimbundo, a que se juntaram referências históricas e religiosas portuguesas (MOURÃO, 1996). Luanda integra, assim, uma cidade religiosa, uma cidade civil, uma cidade dos militares, uma cidade-acampamento, uma cidade feitoria e uma cidade colónia de povoamento (MOURÃO, 1997). Do século XIX ao século XX - com base em políticas administrativas, na diferenciação de ocupações e na chegada de novos habitantes vindos do mato, e da metrópole colonial - a cidade organizou-se em torno do asfalto e dos musseques. Essa transformação, que se intensifica com os trabalhos de saneamento básico e de urbanização do pós-Segunda Guerra Mundial, corresponde a uma hierarquização econômica e racial, matizada pelos chamados bairros "populares" onde mestiços, assimilados e brancos pobres, construíram uma identidade luandense própria (NASCIMENTO, 2013).

Os sucessivos planos de fomento gizados pelo Estado Novo português (1926-1974) para as colônias africanas, a partir dos anos 1940 do século XX, contemplaram a criação de infraestrutura de comunicações viárias e portuárias, tendo sido Angola, e principalmente a capital Luanda, uma das regiões mais beneficiadas. Nesse contexto, estradas e caminhos-de-ferro ligaram as principais cidades, o que favoreceu o aumento populacional das capitais de distrito, mas principalmente Luanda, que à data da independência teria cerca de 600 mil habitantes. A guerra civil pós-independência, com a destruição massiva das infraestruturas existentes, empurrou os habitantes das províncias fustigadas do interior rural, para as cidades litorais angolanas, na condição de desalojados e refugiados. Luanda cresceu rapidamente em população ao receber cerca de 4 milhões de habitantes, o que teve como consequência a expansão de uma "cidade espontânea", caracterizada pelo desenvolvimento deficitário em áreas como o saneamento básico, a energia e a habitação, bem como a ausência de investimentos em equipamentos sociais, tais 
como escolas e hospitais (RAMOS; NETO; FERREIRA, 2004, p. 212). Como consequência, proliferaram os bairros de construção precária, os musseques, enquanto se degradou o parque habitacional do centro da cidade, em grande parte construído no período colonial e ocupado por angolanos, aquando da fuga dos portugueses para a metrópole portuguesa. Esta é a realidade vivida pelas personagens, em Os transparentes, que habitam um prédio em acelerado estado de degradação, no centro de Luanda, mais especificamente na Maianga, um dos bairros mais centrais da cidade:

[...] o Prédio tinha sete andares e respirava como uma entidade viva... havia que saber os seus segredo, as características úteis ou desagradáveis das suas aragens, o funcionamento dos seus canos antigos, os degraus e as portas que não davam para lugar algum [...] (ONDJAKI, 2012, p. 16).

Essa realidade não se altera, após o fim da guerra civil, com a morte do líder da UNITA, em 2002, embora o aumento do preço do petróleo, a paz e os planos de reconstrução, muito apoiados pela China, tivessem gerado índices de crescimento do PIB, entre 2002 e 2008, de cerca de $10 \%$. O crescimento não se traduziu num aumento no IDH (Índice de Desenvolvimento Humano) constituído pelos indicadores de PIB per capita, acesso à educação e saúde. Os aumentos verificados nesse índice, em Angola, que ocupa a 149 ${ }^{a}$ posição, entre 189 países, devem-se, sobretudo, ao aumento do PIB per capita - crescimento dos muito ricos e ricos, não se refletindo em aquisições de bem-estar social, educação e saúde.

Nesse período, a cidade ultrapassou os 6 milhões de habitantes e constitui hoje um dos maiores e mais densos centros urbanos da África Austral, numa área de cerca de $3.000 \mathrm{~km}^{2}$, segundo dados do Plano Diretor Geral Metropolitano de Luanda (PDGML). ${ }^{7} \mathrm{Na}$ atualidade, os musseques que albergam a maior parte da população, são de autoconstrução, apresentam graves problemas estruturais e representam cerca de

7 O Plano Diretor Geral Metropolitano de Luanda (PDGML) foi apresentado no Palácio da Justiça em Luanda, em 14 de dezembro de 2015, com o objetivo de orientar as decisões de planeamento estratégico para a cidade de Luanda (Alexandre, 2016: 89) 
$80 \%$ da geografia urbana da cidade de Luanda. O primeiro quartel do século XXI vem consagrar, na cidade, os projetos de reconstrução nacional e os investimentos no imobiliário e na requalificação da capital, à sombra do PDGML. Nesse enquadramento, foram requalificados o centro e a marginal da cidade velha, acompanhados de demolições de edifícios históricos, e cresceram as cidades satélites modernas, situadas em locais distantes e aprazíveis, sem acesso a infraestruturas públicas (ALEXANDRE, 2016, p. 81-82). Como consequência, o trânsito na cidade tornou-se caótico, dada a inexistência de novos acessos e à detrioração das vias existentes. Dessa realidade, e de forma ficcional e humorística, dá conta Ondjaki ao narrar o quotidiano e a hierarquização social, a partir do acesso a veículos motorizados e formas de deslocação para e dentro da cidade de Luanda:

[...] na avenida o trânsito era intenso, motas de fabrico chinês circulavam por entre os carros enormes, jipes de marca americana, japonesa e coreana, muitos hiace na candonga de transportar o povo que realmente só se podia deslocar de candongueiro, muitos toyota starlet, também conhecidos como gira-bairro, também no serviço de candonga mas este ilegal e mais arriscado... [...] (ONDJAKI, 2012, p. 70).

O narrador descreve, também, o descaso dos serviços públicos pela "coisa pública" ao relatar a degradação das ruas e a supremacia de interesses privados, referindo aspectos que indiciam negócios associado a família do ex-presidente e da elite que a rodeava, ${ }^{8}$ como por exemplo as telecomunicações.

[...] a cidade estava um caos com obras novas e antigas a acontecer ao mesmo tempo, mais as tais escavações da CIPEL ${ }^{9}$, mais os buracos para a instalação de televisão a cabo, mais os buracos da chuva e os buracos

8 Cfr.: BRITO, Ana; VILLALOBOS, Luís. UNITEL: A empresa que lançou Isabel dos Santos, 17/02/2020. Disponível em: https://www.publico.pt/2020/02/17/economia/noticia/ unitel-empresa-lancou-isabel-santos-1904236.

9 No romance, o autor ficciona um possível plano para encontrar petróleo no subsolo de Luanda, onde é criada uma Comissão Instaladora do Petróleo Encontrado em Luanda (CIPEL) (Os transparentes, p. 91). 
abertos que ninguém se lembrara de pavimentar... [...] (ONDJAKI, 2012, p. 112).

Os investimentos imobiliários constituíram desígnios administrativos e, simultaneamente, grandes negócios, por vezes obscuros, da nomenclatura do MPLA. As atividades foram denunciadas ao longo do governo do ex-presidente por organizações internacionais e ativistas nacionais, como a Transparência Internacional ${ }^{10}$ ou o jornalista Rafael Marques. ${ }^{11}$ As atuais investigações, realizadas no âmbito do Luanda Leaks à filha do ex-presidente José Eduardo dos Santos, Isabel dos Santos, permitiram, recentemente, construir a teia de interesses e de apropriação dos recursos de Estado, implementada pela família e associados, com a cumplicidade internacional, nomeadamente portuguesa. ${ }^{12}$ Essa investigação jornalística que rastreia as relações entre o governo, investidores angolanos e internacionais, nos projetos de requalificação de Luanda, relaciona a empresa Urbinveste: Promoção e Projetos Imobiliários SA, na posse de Isabel dos Santos, à multinacional Broadway Malyan. Em simultâneo, a investigação apura irregularidades na execução do projeto Marginal da Corimba, que visava criar um corredor urbano junto à costa, com o objetivo de ligar o sul de Luanda ao centro da cidade. ${ }^{13}$

Ondjaki ao ficcionar, em Os transparentes, uma possível exploração de petróleo no subsolo da cidade de Luanda, descreve, igualmente, de forma humorística, os interesses estrangeiros envolvidos em Angola, quer no comércio, quer na exploração de petróleo:

[...] a mesma troika de sempre , Angola, EUA e Rússia...e os tugas ...ficam com as sobras, mas como há aí uns casamentos e uns billhentes de

10 Disponível em: https://www.transparency.org/en/publications/cpi-2013\#.

11 Rafael Marques acusa figuras do Estado de Angola de branqueamente de capitais. DW-Angola, 17/07/2012. Disponível em: https://www.dw.com/pt-002/ rafael-marques-acusa-figuras-do-estado-de-angola-de-branqueamento-de-capitais/a-16103515.

12 Cfr.: Luanda Leaks. Expresso. Disponível em: https://expresso.pt/luanda-leaks.

13 LOPES, Diogo; VINHAS, Nuno. A "visão" de Isabel dos Santos para Luanda rendeu 500 milhões, mas desalojou três mil pessoas. Jornal O Observador, 21/01/2020. Disponível em: https://observador.pt/2020/01/21/a-visao-de-isabel-dos-santos-para-luanda-rendeu-500-milhoes-mas-desalojou-tres-mil-pessoas/. 
identidade tirados à pressão, pode ser que o tuga coma um pouco mais... [...] (ONDJAKI, 2012, p. 126). ${ }^{14}$

Luanda torna-se, deste modo, uma metáfora de Angola, onde o autor sintetiza os problemas de sobrevivência do país, do Estado e da população, num contexto complexo e heterogêneo, condicionado por fatores inerentes a um capitalismo selvagem e periférico, pautado por interesses multinacionais, mas onde têm grande relevância elementos de foro socioculturais e históricos (HODGES, 2002).

[...] Luanda fervia com a sua gente que vendia, que comprava para vender, que se vendia para ir depois vender, que se vendia para ir depois comprar e gente que se vendia sem voltar a conseguir comprar... [...] (ONDJAKI, 2012, p. 72).

Como refere Hodges (2002), os governantes do MPLA, ao abandonarem o socialismo de Estado no ínico da década de 1990, entraram num capitalismo exacerbado e assente em mecanismos obscuros e autoritários. As eleições e as instituições consolidaram intereses de elites extrativas que dominaram os recursos e as concessões diamantíferas e petrolíferas, as maiores riquezas de Angola, em seu proveito ou de interesses estrangeiros corrompidos e corruptores. Esses interesses criaram teias de clientelismo na sociedade e minaram, de forma devastadora, reformas sociais e investimentos em saúde, educação e na criação de emprego.

\section{Personagens: resistência e cumplicidade}

Baccega (1990, p. 145) no artigo anteriormente citado sobre Mayombe escreve que “...a Ficção concretiza a História através da figurativização a partir de personagens que ganham vida dentro da própria obra”.

14 Conversa entre Davide Airosa, cientista, e Paulo Pousado, jornalista, onde se faz referência aos interesses instalados em Angola, bem como ao casamento, muito mediatizado de uma das filhas do ex-presidente, José Eduardo dos Santos, com um empresário português (Os transparentes, p. 126). Sobre o casamento, consultar: https:/www.cmjornal.pt/mundo/detalhe/ casamento-de-tchize-e-hugo. 
Antonio Candido (2007) considera que a personagem pode ser reconhecida, isto é, identificada, pelo que o narrador informa a seu respeito, isto é, pelo que fala de si próprio ou pelo que outras personagens dizem sobre ela. Em Os transparentes, o narrador recorre a estratégias complexas de apresentação e construção das personagens, no sentido de expressar tipos sociais ou, muito frequentemente, estereótipos que sintetizem a população, não só de Luanda, mas também de Angola. Para este efeito, colaboram os nomes das personagens, como, por exemplo, MariaCom Força, CamaradaMudo, CienteDoGrã, JoãoDevagar, AvóTeta, PauloPousado, Pomposa, DestaVez e DaOutra, VendedorDeConchas ou Cego. Nomes que sintetizam histórias de vida e características físicas e morais, como as que são traçadas em seguida:

[...] CienteDoGrã, filho mais velho de Odonato, passou a adolescência errando de bar em bar, foi sócio de uma afamada discoteca mas terminou como porteiro sempre atrasado, roubou agulhas numa farmácia chegando a costumeiro consumidor de heroína e, na sua tardia juventude, inserido num grupo rastahfari de Luanda...desorientado pela vocação, acordava cedo para ter mais tempo de não fazer nada, e alimentava a obsessão de vir a ter um jipe americano GrandCherokee, os amigos batizaram-no "Ciente do GrandCherokee" e rapidamente foi abreviado para CienteDoGrã ... [...] (ONDJAKI, 2012, p. 25).

As personagens constroem-se, igualmente, a partir das acções que praticam, pelo pensamento que expressam, pelos diálogos, solilóquios, monólogos e fluxos de consciência. Nessa perspetiva, em consonância com Candido (2007, p. 58-59), a construção de personagens na ficção literária exige, ao autor, a capacidade de interpretação e compreensão das pessoas e um olhar longitudinal, e transversal, que permita conferir unidade à diversidade essencial de cada pessoa. Em simultâneo, as personagens adquirem solidez, a partir da memória e das experiências do autor, revificadas pelo narrador e alicerçadas em vivências, expectativas e frustrações. Nesse contexto, o autor Ondjaki "corresponde a uma entidade real e empírica" [...] enquanto o narrador "funciona como entidade fictícia a quem, no cenário da ficção, cabe a tarefa de enunciar 
o discurso da comunicação narrativa" (REIS; LOPES, 2002, p. 257). O jogo do narrador é dar vida a personagens fundadas na vivência do autor, utilizando memórias, observações e experiências, capazes de atribuir consistência interna - no interior do romance - e externa, isto é, tornar as pesonagens inteligíveis aos leitores.

Na apresentação das personagens, há uma dualidade social, e moral, entre aquelas que são "naturalmente perdedoras", numa sociedade capitalista, mas transportam em si valores morais e éticos, e aqueles que são “vencedores" abdicando desses princípios. As figuras resilientes e nostálgicas de Odonato, o transparente, da AvóKunjize, mulher velha de etnia umbundu, e de Paizinho, chegado do Sul, trazem em si as memórias de uma outra vida, de uma outra história, situada numa Angola que lutou pela sua independência, sofreu nessa luta, mas se orgulha do seu percurso, dos seus valores tradicionais e da sua identidade. No entanto, grande parte das personagens encontram-se num limbo, entre os "perdedores" e os "vencedores", quando, para sobreviverem, entram em "esquemas" de natureza duvidosa, embora surja uma longínqua esperança, na mudança do quotidiano...

$[\ldots]$ acabou o tempo de lembrar/choro no dia seguinte/as coisas que devia chorar hoje ... [...] (ONDJAKI, 2012, p. 9).

Odonato, o transparente, a AvóKunjize, mulher velha de etnia umbundu, e Paizinho, chegado do Sul, alicerçam a sua resiliência em "acontecimentos vividos pessoalmente" mas, também, em "acontecimentos vividos pelo grupo ou pela coletividade à qual a pessoa se sente pertencer" (POLLAK, 1992, p. 200-212), nomeadamente na luta de libertação e nos primeiros anos da independência de Angola. Ambos os acontecimentos estão presentes nas três personagens que recorrem, simultaneamente, à sua memória individual, mas também à memória coletiva, convocando pessoas e heróis, acontecimentos e histórias de um outro tempo, de um outro espaço e de uma outra geografia, o que lhes permite refazer, quotidianamente, enquadramentos de memória e lembrar uma outra vida. Evocam, como escreve Barone (2005, p. 179-180), 
"modos de memória" que se encontram "associado(s) à temporalidade social" e permitem "modos de viver o tempo". Trata-se de um recurso cognitivo que envolve características sociocorporais e culturais que tornam a memória não só um "instrumental cognitivo do sujeito" mas, também, uma ferramenta de "transformação social".

Ilustrativa é a conversa entre Odonato, sua mulher e a AvóKunjikise que, num presente decepcionante, recupera a lembrança de uma outra vida, em uma outra Luanda e Angola, de esperança, nos anos após a declaração da independência:

[...] - começaram as desgraças...espero que Deus não esteja a domir murmurou AvóKunjikise

Odonato parecia absorto,? pela janela, em busca de um lugar dentro do tempo

- julgo que sofro da doença de mal-estar nacional - disse à esposa, sorrindo levemente...o país dói-me...a guerra, os desentendimentos políticos, todos os nossos desentendimentos, os de dentro e os que são por aqueles que são de fora....

os seus olhos e o seu corpo sentiam profunda saudade dos passeios domingueiros com a família, para perto do mar, no chamado BairroDaIlha....

Luanda era então, se comparado com a atualidade, um quase deserto urbano onde faltava a comida e a roupa, os medicamentos, sem água e sem luz, muitas vezes faltava cerveja ou vinho...os sapatos estavam gastos mas as pernas felizes ...e até as pessoas eram mais brandas... [...] (ONDJAKI, 2012, p. 179-180).

Esse excerto, para além dos “modos de memória”, carrega nostalgia, entendida no sentido primordial grego de "dor prolongada" pelo afastamento de "casa", isto é, a memória de uma outra vida, numa outra Angola, onde se estava confortável. Essa nostalgia, que envolve melancolia, expressa um estado de espírito que articula o presente - onde se vive, mas se sente estranho - e um passado, onde se imagina ter estado em casa (PICKERING; KELGHTLEY, 2006). O sentimento de nostalgia perpassa não só esta fala de Odonato, mas muitas outras de diferentes personagens que sobrevalorizam vivências do passado, em face das dificuldades, estranheza e incompreensão do presente, como o Carteiro. 
[...] o tempo passou e houve coisas que ficaram perdidas, respeito, moral, os bons costumes.... [...] (ONDJAKI, 2012, p. 80).

A riqueza das personagens, criada pelo narrador, está na diversidade e na capacidade de sintetizar tipos sociais, de forma simplificada, o que permite o reconhecimento imediato da personagem na sociedade. A descrição do tipo social surge, nesse sentido, como estereótipo, uma simplificação da informação que envolve um processo cognitivo de categorização social, capaz de reduzir a ansiedade sociocultural ao tornar possível o compartilhamento de imagens mentais, por indivíduos ou grupos. Esse processo, adotado pelo narrador, reflete as imagens que os grupos têm de si mesmos, na forma de auto-estereótipo, mas também as imagens que os grupos têm de outros grupos, como heteroestereótipos (LEYENS, 1985, p. 55). Um jogo de espelhos entrelaçado de imagens mútuas.

Com base nesse procedimento as personagens compõem uma teia social, que envolve quer os mais humildes - por exemplo o VendedorDeConchas e o Cego - quer os mais informados - PauloPousado, o jornalista; DavideAirosa, o cientista - quer, ainda, as forças obscuras da sociedade, nomeadamente um Ministro, interessado na exploração de petróleo; um Assessor, subserviente e prepotente ou, ainda, um empresário vencedor, como DomCristalino:

[...] RibeiroSeco, o homem que chamavam DomCristalino, por estar há muitos anos envolvido com questões aquáticas, trabalhara anos no MinistérioDaIndústria, passando por outros postos no tempo do falecido Socialismo-Esquemático e foi privatizando os lugares, as fábricas e até algumas das pessoas que se viram envolvidas com o seu trajeto.... [...] (ONDJAKI, 2012, p. 165).

As mulheres têm, na generalidade, pouca expressão em Os transparentes, exceto as mais velhas, como a AvóKunjikise ou a AvóTeta. Ambas assumem autoridade pelo seu percurso de vida, experiência e idade, apesar dos seus percursos serem muito diferentes. Enquanto a primeira, de etnia e língua umbundo, chega a Luanda fugida da guerra e é 
adotada pela família de Odonato, onde toma o lugar da avó acabada de enterrar; a segunda vive na cidade há muito, onde organizou, num bairro popular, um negócio de prostituição, onde cuida e dá trabalho a moças abandonadas. Todas as outras mulheres surgem como "coadjuvantes" de personagens masculinas, ora como mulheres dedicadas e atenciosas, ora como amantes/namoradas.

Independentemente dessa condição de "coadjuvante", as mulheres são ficcionadas, na generalidade, como possuindo personalidades fortes e resilientes, como MariaComForça, que vende comida na rua e outras bugigangas. No entanto, elas não se conseguem libertar da sua condição de subserviência diante dos homens, em função da sua dependência emocional. Clara, a namorada do jornalista PauloPousado, é uma das mulheres com maior independência nas escolhas e opções, nomeadamente sexual, dentro de um quadro urbano de trabalho e sociabilidade.

O esbatimento da autonomia feminina, não significa, apesar de tudo, irrelevância, pois são essas mulheres que dinamizam as personagens masculinas, mas espelha, sem dúvida, as dificuldades de afirmação da maioria das mulheres, nas sociedades africanas. ${ }^{15}$ Paradoxalmente, a única mulher com autonomia intelectual, emocional e profissional é uma jornalista da BBC, a que não é atribuído nome, e que se propõe a investigar e a relatar o que se passa em Luanda e em Angola, dando, simultaneamente, voz ao povo.

\section{As Mídias como pano de fundo}

O romance Os transparentes comporta uma dimensão mediática que acompanha o enredo, sendo que muitas das personagens assumem, ou afinam, os seus elementos identitários, a partir do consumo de produtos mediáticos como ler o jornal, ligar a $\mathrm{CNN}$, assistir a telenovela brasileira, ver filmes, incluindo os para adultos, ou ainda ouvir jaz, ou música angolana dos anos 80 .

15 Disponível em: https://unesdoc.unesco.org/ark:/48223/pf0000230162. 
O panorama mediático angolano é regulado pela Constituição de Angola, revista e aprovada em 2010, que consagrou, em diversas adendas, o direito à Liberdade de Expressão e de Informação e a proibição de censura. No contexto em que se desenrola o romance, apesar da legislação em vigor, o sistema mediático angolano continuou a ser controlado, e monopolizado, pelo partido do governo, o MPLA.

Nos anos a que se refere Os transparentes, a imprensa escrita tem cerca de 13 jornais, entre públicos (3) e privados (10), enquanto a Rádio Nacional de Angola domina $80 \%$ do mercado, embora estejam a operar mais de 12 estações de rádio privadas, incluindo a Emissora Católica de Angola (Gaspar, 2015, p. 18). No âmbito da Televisão assinala-se a Televisão Pública de Angola (TPA), que “exerce as suas atividades em regime de monopólio de Estado, com três canais, com abrangência nacional e internacional: Canal 1, Canal 2 e a TPA Internacional" (GASPAR, 2015 , p. 19). Foram, no entanto, concedidas licenças a grupos privados, da confiança do governo e das elites instaladas, como, por exemplo, ao Grupo Media Nova e à TV Zimbo ${ }^{16}$ e à Banda TV (canal pago). O setor privado, muito instável, em função das condicionantes econômicas, sociais e ideológicas de atuação, é constituído por grupos nacionais e filiais de grupos internacioanais, nomeadamente portugueses e brasileiros que são oferecidos através de Pay TV. Marcam presença as televisões portuguesas, nas suas edições vocacionadas para África (RTP, TVI e SIC) e as brasileiras Globo e Record. A estas televisões juntavam-se emissões de canais europeus, nomeadamente da BBC, canais americanos a cabo, como o AXN e a FOX, e sul-africanos.

As mudanças tecnológicas na televisão que aconteceram na primeira década do século XXI, que determinaram a passagem do analógico para o digital, estão assinaladas na forma como é descrito o terraço do Prédio, epicentro da história e morada do protagonista e das personagens centrais de Os transparentes: 
[...] ali dormiam quietas ou bailavam ao vento as inúmeras antenas, as de antigamente, envelhecidas, tortas ou mesmo cambaleantes, e as mais recentes, pequenas e grandes parabólicas, dessas que apanham notícias e vozes de outros lugares mais internacionais.... [...] (ONDJAKI, 2012, p. 52).

O papel dos órgãos do governo e de monopólio de Estado da Rádio de Angola e da Televisão de Angola, surge em diferentes momentos, pautando decisões do governo, do "Chefe", do "Presidente". As declarações emitidas em direto, trazem discursos de Estado em registo burocrático elaborado, e anunciam disposições gerais que escondem factos, muitas vezes ocultos e danosos, aos cidadãos comuns.

Por exemplo, quando o Presidente fala aos microfones da Rádio Nacional, a propósito do cancelamento do "eclipse" - um acontecimento anunciado pelo governo como único em Angola, que atraíria muitos turistas e seria oportunidade para festejos nacionais - por "falecimento da camarada ideologia”. O trecho evoca, na verdade, uma metáfora dos desvios realizados pelo governo e dos enganos vendidos ao povo angolano, cujo discurso, na Rádio, começa da seguinte forma:

[...] caros cidadãos da RepúblicaDeAngola, demais representantes de outras nações acreditadas no nosso país, entidades religiosas e cívicas: em nome do governo nacional de Angola e segundo um encontro extraordinário do birô político do Partido, cumpro o dever de informar uma decisão que terá implicações na vida social, política e cultural de cada um de nós.... (ONDJAKI, 2012, p. 362).

A TPA e a Rádio Nacional acompanham o quotidiano das personagens, difundindo informações sobre as medidas adotadas pelo governo, mas também há referências a programas de interesse público, como a recolha de música tradicional que a Rádio Nacional fez, ou, ainda, o programa da TPA, "Ponto de Encontro", que promove encontros entre famílias separadas pela guerra civil.

A dificuldade do exercício do Jornalismo em Angola; as ameaças quotidianas a que os profissionais estão sujeitos, nomeadamente físicas e psicológicas; as pressões políticas e econômicas, bem como as diferentes 
formas do regime cercear a independência e a liberdade de expressão, constituem uma realidade do quotidiano em Angola. ${ }^{17}$ Ilustra essa realidade uma das personagens mais trágicas do romance, o jornalista PauloPousado, que, ao estar por dentro das tramas políticas e econômicas, decide assassinar o Presidente e acaba por ser abatido, com um tiro na testa, pelos GuardaAsCostas. A sua personagem emerge como uma metáfora do Jornalismo em Angola, onde muitos jornalistas foram perseguidos e mortos no período em que o romance decorre. ${ }^{18}$ PauloPousado expressa a angústia, entre quem se vê pressionado por um conformismo situacionista e a liberdade de imprensa e de expressão, consagrada na constituição:

[...] o chefe convocara uma reunião que não convinha recusar, as coisas não andavam bem no trabalho, demasiadas reclamações e ausências, para não mencionar as divergências ideológicas que orientavam o trabalho de cada um deles, se por vezes o chefe assumia ares de liberal que queria dar o bom exemplo no seio da comunicação nacional, outras vezes eram evidentes os seus compromissos com membros da alta esfera do.... [...] (ONDJAKI, 2012, p. 83).

A saída radical que o jornalista vislumbra ao planejar a morte do Presidente compagina-se com a solução dramática que o narrador encontra para finalizar o romance: a explosão do Prédio, e de Luanda, e a morte de Odonato.

[...] todos os horizontes eram um mar de chamas amarelas e fumos confusos, diminuíam os ruídos para depois se voltarem a alimentar de explosões outras...do bolso esquerdo Odonato retirou um minúsculo papel e, sob um olhar seco de despedida e ternura, escrevinhou umas linhas rápidas para depois se debruçar sobre si mesmo e roer com os dentes caninos o pedaço de corda que o atava ao prédio... [...] (ONDJAKI, 2012, p. 421-422).

17 Disponível em: https://www.dw.com/pt-002/angola-acusa\%C3\%A7\%C3\%A3o-a-jornalistas-espelha-press\%C3\%A3o-do-governo-em-tempo-de-elei\%C3\%A7\%C3\%B5es/a-39480522; https://www.dw.com/pt-002/aumenta-press\%C3\%A3o-contra-imprensa-angolana/a-44328461.

18 Disponível em: https://www.voaportugues.com/a/ano-2013-foi-pessimos-para-os-jornalistas-angolanos-misa/l783347.html. 
Ao longo do romance outras empresas de mídia são mencionadas, como a CNN, a Globo, a RTP e a BBC. As referências às outras estações internacionais são dispersas, mas a BBC surge na figura de uma jornalista que procura entender o que se passa com Odonato, e com a causa da sua tranparência. Contudo, ela não tem grande convicção que as suas matérias jornalísticas sejam publicadas e comenta que "já não manda nada para a BBC. Eles não querem... ninguém quer boas notícias sobre Angola ou sobre África” (ONDJAKI, 2012, p. 281-282).

No panorama mediático destacam-se as menções às telenovelas e aos profissionais de mídia de origem brasileira. Recorda-se, aqui, que no percurso intelectual da Professora Baccega, os estudos sobre a telenovela, produção e recepção receberam grande atenção. Num artigo publicado na Revista Educação \& Comunicação, em 2003, a autora escreve que "os meios de comunicação, em especial a televisão" são o "lugar privilegiado da narrativa, cujas matrizes históricas se encontram naquelas manifestações culturais" (BACCEGA, 2003, p. 9). No mesmo artigo refere que "A televisão e a ficção televisiva em geral ...pelo próprio formato do género...conseguem, de maneira muito mais ágil, expôr conceitos e caminhar com êxito no sentido da persuasão da população em geral" (BACCEGA, 2003, p. 8). Ao explorar esta questão associa os jornais televisivos à telenovela considerando que os primeiros são na generalidade muito mais "ficção" que a ficção telenovela. Na senda destas afirmações é necessário compreender o papel e a presença das telenovelas brasileiras no quotidiano luandense, tendo em conta as relações seculares que envolvem trocas culturais e econômicas entre Brasil e Angola (CUNHA, CASTILHO; GUEDES, 2017). O sucesso das telenovelas insere-se numa linha do tempo de trocas simbólicas, que envolve acontecimentos e situações como a escravatura, as religiões tradicionais africanas, a literatura de expressão portuguesa e a música popular brasileira. As telenovelas brasileiras, em Angola, têm público desde o início da década de 80 do século passado e, desde então, estão presentes no quotidiano luandense. 
Em outros romances, como Os da minha Rua (CUNHA, 2020, p. 35-62), Ondjaki expôs o poder das telenovelas brasileiras em estimular, no quotidiano, imaginários possíveis e, ao mesmo tempo, permitir a fuga a realidades sofridas pela população em Luanda. Em Os transparentes o mesmo sentimento, de fuga ao quotidiano, está presente e não só a telenovela desperta processos de identificação, como constitui um marco temporal das famílias e da sociedade luandense, como "chegar a casa depois da novela", "trabalhar à hora da novela", falar como "Odorico Paraguaçu".

A projecção das mídias brasileiras por meio das telenovelas e das grandes empresas que as produzem, levou para Luanda técnicos e profissionais qualificados encarregados de operar estes dispositivos. Ao mesmo tempo, gerou entre os angolanos uma grande familiaridade com o linguajar do Brasil, fazendo com que se adotassem vocábulos e expressões. Esta próximidade trouxe, também, as igrejas evangélicas para Angola que, no romance, surge ilustrada pela IgrejaDaOvelhaSagrada, descrita de forma humorística, como uma oportunidade de negócio seguro. É de ressaltar que as igrejas evangélicas brasileiras, em Angola, têm estado no centro de numerosas polémicas, não só pela questão dos dízimos, como pela questão ideológica. ${ }^{19}$

Referências à indústria cultural são também constantes em Os transparentes, uma característica dos romances de Ondjaki que, nessa obra, enuncia - muitas vezes dentro de um enquadramento nostálgico, relativo aos anos de luta colonial, ao período de pós-independência, ou ainda da guerra civil - músicos angolanos como Bonga, RuyMingas, CarlosBurity, WaldemarBastos ou PauloFlores.

\section{Apontamentos finais em jeito de conclusão}

O romance Os transparentes é, ao contrário de Mayombe de Pepetela, uma obra desesperançada. No momento em que Baccega escreveu e analisou Mayombe, no seu doutoramento, estava aparentemente

19 Disponível em: https://www.hypeness.com.br/2018/11/por-que-angola-esta-fechando-igrejasevangelicas-no-pais/. 
traçado o caminho da independência e da liberdade em Angola. No momento que Ondjaki escreveu Os transparentes passaram muitos anos sobre aqueles acontecimentos, uma guerra civil implacável destruiu muitas vidas e muitos sonhos e instalou-se um capitalismo selvagem, com poucos beneficiários e muitos perdedores.

Ao contrário de Pepetela, Ondjaki não aponta caminhos para um futuro que traria a paz, a prosperidade e a concórdia entre etnias e raças. Em consonância com o protagonista Odonato, o transparente, o narrador sofre e descreve, de forma nítida, muitos elementos indiciadores de fim de regime e de ansiedade perante o que possa vir a trazer o futuro. Ao iluminar uma galeria de personagens que lutam pela sobrevivência, em diferentes estratos da sociedade, onde parece terem desaparecido os parâmetros de convivência e solidariedade, só o povo, descrito, em abstrato, como "...belo, dançante, arrogante, fantasioso, louco, bêbado..." (ONDJAKI, 2012, p. 283) parece poder mudar o curso da história.

\section{Referências}

ALEXANDRE, Luís Herlander Sebastião. Luanda, da arquitetura vernácula ao séc. XXI: Uma tipologia de habitação para Luanda. Dissertação de Mestrado, Universidade Lusófona de Humanidades e Tecnologias, Departamento de Arquitetura, Lisboa, 2016.

ALEXANDRE, Valentim. Ideologia, economia e política: a questão colonial na implantação do Estado Novo. Análise Social, v. 123-124, n. 4 e 5, p. 1117-1136, 1993. Disponível em: http://analisesocial.ics.ul.pt/documentos/1223294012K3eBJ5whlAf89 UW6.pdf.

ALEXANDRE, Valentim. O império português (1825-1890): ideologia e economia. Análise Social, v. XXXVIII, n. 169, p. 959-979, 2004. Disponível em: http://analisesocial. ics.ul.pt/documentos/1218650604I3uCQ0xh3Fc45BI0.pdf.

BACCEGA, Maria Aparecida. O movimento entre a ficção e a história: o caso Mayombe. Revista África, n. 12-13, p. 137-148, 1990. Disponível em: https://doi.org/10.11606/ issn.2526-303X.v0i12-13p137-148.

BACCEGA, Maria Aparecida. Narrativa Ficcional de Televisão: encontro com os temas sociais. Comunicação \& Educação, 26, 7 a 16 de jan., p. 1-16, 2003.

BARONE, António Fernando. Memória Cotidiana e Comunicação. Comunicação \& Educação, Ano X, n. 2, maio/agosto, p. 179-193, 2005.

BURNAY, Catarina Duff. Identidade e identidades na ficção televisiva nacional: 20002006. Lisboa, Revista Comunicação ङ Cultura, n. 1, 2006, p. 57-71. 
CANDIDO, Antonio. A personagem do romance. In: CANDIDO et al. A personagem de ficção. 11. ed. São Paulo: Perspectiva, 2007, p. 51-80.

CRESWELL, John W. (Ed.). Research Design: Qualitative, Quantitative, and Mixed Methods Approaches (3. ed.). Los Angeles: Sage, 2009.

CUNHA, Isabel; CASTILHO, Fernanda; GUEDES, Ana Paula (Org.). Ficção Seriada Televisiva no Espaço Lusófono. Covilhã: LabCom, 2017. Disponível em: http://www. labcom-ifp.ubi.pt/book/293.

CUNHA, Isabel. Os da minha Rua de Ondjaki: a ficção na memória e construção da identidade na Luanda pós-independência, p. 35-62. In: SILVA, Lourdes Ana P.; GUARANHA, Manoel Francisco; BASEIO, Maria Auxiliadora (Org.). Identidades Ficcionais: narrativas literárias e televisivas. Covilhã: LabCom. Disponível em: http://labcom.ubi. pt/livro/347.

FREDERICO, Celso (2020). Multiculturalismo em quarentena. A terra é redonda: eppur si muove. Disponível em: https://aterraeredonda.com. br/o-multiculturalismo-em-quarentena/.

GAMBETTA, Diego. Corruption: An Analytical Map. In: KOTKLIN, Stephan e SAJÓ, Andras. Political Corruption in transition: a sceptic's handbook (p.33-56). Budapeste: Central European University Press, 2002.

GOLDMANN, Lucien. Ciências Humanas e Filosofia. São Paulo: Difel, 1974.

GONÇALVES, Jonuel. Questões sobre a história económica de Angola da fundação de Luanda ao começo do ultracolonialismo. Centro de Estudos Internationales para el Dessarrolo, 2010. Disponível em: http://www.ceid.edu.ar/serie/2010/ceid_dt_50_ angola_a_fundacao_de_luanda_ao_comeco_do_ultra_colonialismo.pdf.

HODGES, Anthony. Angola. Do Afro-Estalinismo ao Capitalismo Selvagem. Cascais: Princípia, 2002.

LEYENS, Jacques-Philipe. Teorias da personalidade na dinâmica social. Lisboa: Verbo, 1985.

MIGUEL, Nilza Karina Gaspar. A Regulação da imprensa em Angola. Dissertação com vista à obtenção do grau de Mestre em Direito Empresarial. Universidade Nova de Lisboa. Faculdade de Direito, março de 2015. Disponível em: https://run.unl.pt/ handle/10362/20304.

MOURÃO, Fernando Augusto de Albuquerque. A evolução de Luanda: aspectos socio-demográficos em relação à independência do Brasil e ao fim do Tráfico. Revista II RIHA, p. 57-73, 1996. Disponível em: https://edisciplinas.usp.br/pluginfile.php/358911/ mod_resource/content/1/A\%20evolu\%C3\%A7\%C3\%A3o\%20de\%20Luanda\%20-\%20 Fernando\%20Mour\%C3\%A3o.pdf. Acesso em: junho 2018.

MOURÃO, Fernando Augusto de Albuquerque. Configuração dos núcleos humanos de Luanda, do século XVI ao século XX. Actas do Seminário do Arquivo Histórico Ultramarino: Encontro de Povos e Culturas em Angola, p. 109-225, 1997.

NASCIMENTO, Washington Santos. Contornos das identidades angolanas: o "crioulo" o "assimilado" e o "angolano" na segunda metade do século XX (1945-1975). Anais do XXVI Simpósio Nacional de História - ANPUH, São Paulo, julho de 2011. 
468 “OS TRANSPARENTES” DE ONDJAKI

NASCIMENTO, Washington Santos. Gentes do Mato: Os novos "Assimilados" em Luanda (1926-1961). São Paulo. Tese de Doutoramento apresentada à Universidade de São Paulo, Departamento de História, 2013.

OLIVEIRA, Ricardo Soares de. Magnífica e Miserável. Angola desde a Guerra Civil. Lisboa: Tinta-da-china, 2015.

ONDJAKI. Os da minha Rua. Lisboa: Ed. Caminho, 2007.

ONDJAKI. Os transparentes. Lisboa: Ed. Caminho, 9. ed., 2012.

PICKERING, Michael; KEIGHTLEY, Emily. The modalities of Nostalgia. Current Sociology, v. 54, n. 6, p. 919-941, 2006.

POLLAK, Michael. Memória e Identidade Social. Rio de Janeiro. Revista de Estudos Históricos, v. 5, n. 10, p. 200-212, 1992.

RAMOS, Natália; NETO, Ana; FERREIRA, Maria Júlia. Desafios e oportunidades na gestão das cidades - o caso de Angola. GEOINOVA, n. 10, 2004.

REIS, Carlos; LOPES, Ana Cristina. Dicionário de Narratologia. Coimbra: Almedina, 2002.

\section{Sobre a autora}

Isabel Ferin Cunha - Licenciada em História, Mestre e Doutora em Ciências da Comunicação pela ECA-USP e Pós-Doutorada no CNRS. É professora associada, com agregação (aposentada), da Faculdade de Letras da Universidade de Coimbra. Coordenou o Obitel em Portugal de 2006 a 2012. Coordenou os projetos Imagens do Feminino na Televisão; Televisão e Imagens da Diferença; Jornalismo e Actos de Democracia; Media, Imigração e Minorias Étnicas e Cobertura Jornalística da Corrupção Política: uma perspetiva comparada Brasil, Moçambique e Portugal (2013-2017).

Data de submissão: 16/06/2020

Data de aceite: $21 / 08 / 2020$ 